\title{
Gastroenteroloji ünitemizdeki kolonoskopi sonuçlarımızla birlikte, endikasyonlar komplikasyonlar ve işlem başarısının değerlendirilmesi
}

Evaluation of colonoscopy outcomes with the indications, complications, and success of the procedure in our gastroenterology unit

Hüseyin KORKMAZ1 , İsmail Can KENDIR², Onur KERPIÇ³

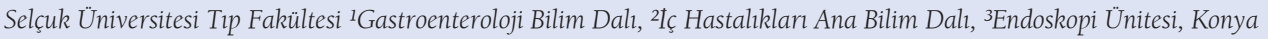

Giriş ve Amaç: Günümüzde kolorektal patolojilerin araştırılmasında en iyi tanısal yöntem kolonoskopi olarak adlandırılan endoskopik incelemedir. $\mathrm{Bu}$ çalışmadaki amacımız, Selçuk Üniversitesi Tıp Fakültesi Gastroenteroloji Bilim Dalı'nda alt gastrointestinal sistem endoskopisi (kolonoskopi) uygulanan hastalarda, işlem endikasyonları, başarı oranı ve komplikasyonları ile birlikte, kolonoskopi sonuçlarının retrospektif olarak değerlendirilmesidir. Gereç ve Yöntem: Gastroenteroloji Endoskopi Ünitesi'nde Ocak 2012 ile Temmuz 2014 arasında çeșitli endikasyonlarla kolonoskopi yapılmış hastaların kolonoskopi raporları endoskopi arşiv sisteminden retrospektif olarak tarand. Bulgular: Toplam 1500 hastaya kolonoskopi yapılmış olup vakaların 764 (\%50.9) ü erkek ve 736 (\%49.1) si kadindı. Yapilan kolonoskopilerin sonucunda \%48.4 hastada herhangi bir patoloji saptanmazken, en sik olarak hemoroid (\%15) ve bunu takiben de ikinci sıklıkta polip (\%13.3) tespit edildi. Kolonoskopi endikasyonları içinde konstipasyon en sık neden olarak tespit edildi. \%21.9 hastada kolon temizliğinin yetersiz olduğu gözlendi. Sonuç: $\mathrm{Bu}$ çalışmamızın sonucunda kolonoskopi endikasyonlarının geniş tutulduğu, ayrıca kolon temizliğinin yaklaşık beş hastanın birinde yetersiz olduğu, bunun da ikinci bir iş yükü ve maliyet getirdiği tespit edilmiştir.

Anahtar kelimeler: Alt gastrointestinal sistem, kolonoskopi, tanı, komplikasyonlar

\section{GİRİș}

Kolorektal kanserler, kanser nedeniyle ölümlerin en sık ikinci nedenini oluşturmaktadırlar (1). Bunlarda erken teşhis çok önemli olup, mortaliteyi \%15-\%33 oranında azaltabilmektedir $(2,3)$. Bundan dolayıdır ki, kolonun incelenmesi, erişkinlerde, özellikle de 50 yaşından itibaren önerilmektedir. Bununla birlikte barsak alışkanlığı değişiklikleri olan, özellikle son zamanlarda ortaya çıkan kabızlık sorunu olan, dışkılama ile birlikte veya sonrasında rektal kanaması olan, uzun süreli kanlı veya kansız ishali olan, gaitada gizli kan pozitifliği ve izah edilemeyen demir eksikliği anemisi olan hastalarda kolonun incelenmesi tavsiye edilmektedir (2).

Günümüzde kolon ile ilişkili semptomların araştırılması ve kolonun incelenmesinde en iyi tanısal yöntem kolonoskopi olarak adlandırlan endoskopik incelemedir. Kolonoskopi 1şıklı fiberoptik veya videoendoskopla, kolonun görsel olarak incelenmesidir (4). Kolonoskopide amaç; rektumdan çekuma
Background and Aims: Currently, colonoscopy is the gold standard to determine colorectal pathologies. Colonoscopy provides an excellent view of the mucosal surface from the anal canal to the terminal ileum. The aim of this study was to retrospectively evaluate colonoscopy results, indications, complications and the success of the procedure between January 2012 and July 2014 at the Gastrointestinal Endoscopy Unit at Selcuk University. Materials and Methods: Retrospective analysis of medical charts and pathological results of patients who underwent lower gastrointestinal system endoscopies during the period 2012-2014 was performed. Results: A total of 1500 patients underwent colonoscopic examinations; 764 (50.9\%) of the patients were male, 736 (49.1\%) were female. Colonoscopic findings were as follows: $48.4 \%$ of the patients had no pathology, $15 \%$ had hemorrhoids, $13.3 \%$ had polyps and $1.4 \%$ colorectal cancers. Colon cleansing was inadequate in $21.9 \%$ of patients presenting for colonoscopy. Conclusion: Approximately half of the patients had normal colonoscopic findings that suggests that the indications for colonoscopy were expanded. One in five patients had inadequate colon cleansing which caused extra effort and cost.

Key words: Lower gastrointestinal system, colonoscopy, indications, diagnosis

kadar tüm kolonun ve terminal ileumun görüntülenmesidir. $\mathrm{Bu}$ işlemin diğer yöntemlere göre üstünlüğü lezyonun görüntülenmesiyle birlikte aynı anda biyopsi alabilme ve polipektomi, dilatasyon, ya da alt gastrointestinal sistem kanamasina yönelik tedavisel yaklaşım olanakları sunmasıdır $(4,5)$.

Bu çalışmadaki amacımız, merkezimizde yapılan kolonoskopilerde; (I) işlem isteme endikasyonlarının, (II) işlemin tamamlanma sıklığı ve tamamlanmasını engelleyen nedenlerin, (III) işlemle ilgili komplikasyonların analizi yanında, kolonoskopide tespit edilen (IV) patolojiler ve bunların makroskopik ve histopatolojik tanılarının retrospektif olarak analiz edilmesidir.

\section{GEREC ve YÖNTEM}

Selçuk Üniversitesi Tıp Fakültesi Gastroenteroloji Bilim Dalı Endoskopi Ünitesi'nde Ocak 2012 ile Temmuz 2014 tarihleri 
arasında kolonoskopi yapılan hastaların, kolonoskopi raporları endoskopi arşiv sisteminden retrospektif olarak taranıp incelendi.

Hastaların, kolonoskopik işleme hazırlamak için işlemden 48 saat önce sulu gıda ile beslenmeleri, işlem öncesindeki akşam $90 \mathrm{cc}$ sodyum fosfatı birer saat ara ile 3 doz halinde oral alması ve işleme kadar en az 4 litre su almaları sağlanarak barsak temizliği yapıldı. Gece 24'den itibaren aç kalan hastalara, işlem için damar yolu açıldıktan sonra IV sıvı takılıp sedatif olarak midazolam 1-5 mg ve 25-50 mg pethidin IV uygun zaman içinde verildi. Tüm kolonoskopik incelemeler Olympus GIF 150 marka kolonoskopi cihazı ile tek gastroenterolog tarafından gerçekleştirildi.

\section{BULGULAR}

Gastroenteroloji endoskopi ünitesinde, endikasyonları tarafimızca konulan toplam 1500 hastaya anal kanaldan-çekuma ve terminal ileuma kadar video kolonoskopi ile endoskopik inceleme yapılmış olup sonuçları retrospektif olarak değerlendirildiğinde; Vakaların 764 (\%50.9) ü erkek ve 736 (\%49.1) sı kadın olup yaşları 18 ile 89 arasında değişmekteydi. Kolonoskopi işlemi endikasyonları ve işlem başarısı ile ilgili veriler Tablo l'de özetlendi. Kolonoskopi işlemi en sık olarak \%22.3 oranında konstipasyon nedenini aydınlatmak için istenmişti. Hastaların \%26.6'sında kolonoskopi işleminin tamamlanamadığı ve bunun en büyük nedeninin \%83 oranında kolonun yetersiz temizliğinden kaynaklandığı gözlendi. Genel olarak tüm hastaların \%21.9'unda yeterli kolon temizliği olmadığı saptandı. Kolonoskopik işlemlerin makroskopik - histopatolojik sonuçları ve yüzdelik dağılımları Tablo 2'de özetlendi. Hastaların \%48.4'ünde kolonosko- pik olarak herhangi bir patoloji saptanmazken, diğer vakalarda en sık görülen patoloji hemoroid idi. Ayrıca yaklaşı \% 1.4 oranında kolorektal kanser belirlendi. Uygulama sirasında bir kadın hastada sedoanestezi işleminden yaklaşık 30 saniye sonra anaflaktik reaksiyon gelişti. Hastanın işlemi sonlandırılıp hemen IV olarak adrenalin, antihistaminik ve prednisolon verilerek yapılan müdahale ile yaklaşık 5-10 dakika sonra hasta normale döndü.

\section{TARTISQMA}

Günümüzde, kolonoskopi tanısal değerlendirmenin yanında biyopsi alma ve tedavisel olarak ta kullanılabilmesinden dolayı halen kolonun ve terminal ileumun incelenmesinde en önemli ve en değerli yöntemdir. Rektal kanama ve kabızlık şikayeti olan hastalarda daha sıklıkla yapılır olmasına rağmen kolonun her türlü patolojik oluşumunun erken tespitinde kolonun endoskopik incelenmesi önemlidir (5). Amerikan Kanser Cemiyeti 50 yaş üstü herkesin yllda bir gaitada gizli kan baktırması ve 3-5 yıllık aralarla rektosigmoidoskopi yaptırmasını önermektedir (6). Kliniğimizde benzer endikasyonlarla kolonun incelenmesi yapılırken, kolonoskopinin en sık olarak konstipayon nedeniyle istenmiş olduğu gözlendi.

Kolonoskopi taramalarının başarısı çekum entübasyonu ile değerlendirilmektedir. Amerikan Toplumu Kolorektal Kanser Görev Gücü (The US Multi-Society Task Force on Colorectal Cancer) çekum entübasyonu başarısının standart kriterini \%90 olarak belirlemiş ve \%95 olması önerilmektedir. Son yıllarda literatürde çekuma ulaşma oranı \%85-92 arası bildirilmektedir (7,8). Adenom tespiti, kolonoskopi endikasyonu, hasta seçimi ve endoskopistin teknik yeterliliği değerlendirmede bir diğer kriter olarak kullanılmaktadır. Bu oran 50 yaş

Tablo 1. Kolonoskopi istemindeki endikasyonlar ve ön tanılar ile çekum ve terminal ileuma kadar ulaşıp inceleyebilme başarısı ile bunu etkileyen faktörler.

$\begin{array}{lccc}\text { Endikasyonlar } & \mathbf{n}(\%) & \text { Kadın, n (\%) } & \text { Erkek, n (\%) } \\ \text { Kabızlık } & 333(22.2) & 186(55.8) & 147(44.1) \\ \text { Ishal } & 297(19.8) & 145(48.8) & 152(51.1) \\ \text { Anemi } & 279(18.6) & 144(51.6) & 135(48.3) \\ \text { Karın ağrısı } & 276(18.4) & 130(47.1) & 146(52.8) \\ \text { Kanama } & 210(\% 14) & 90(42.8) & 120(57.1) \\ \text { Opere kolon kanseri } & 63(4.29) & 20(31.7) & 43(68.2) \\ \text { Kolon kanseri } & 42(2.8) & 21(50) & 21(50) \\ & \text { Kolonoskopi işleminin çekuma ve terminal ileuma kadar tamamlanma başarısı } & 575(52.1) \\ \text { Tamamlandı } & 1103(73.4) & 528(47.8) & 189(47.6) \\ \text { Tamamlanamadı } & 397(26.4) & 208(52.3) & 165(50.1) \\ \text {-Kirli kolon } & 329(21.9) & 24(66.6) & 12(33.3) \\ \text {-Looplanma nedeniyle } & 36(2.4) & 20(62.5) & 12(37.5)\end{array}$


Tablo 2. Kolonoskopik incelemedeki makroskopik ve histopatolojik bulgular ve bunların sayıları, kolon lokalizasyonlanı ve cinsiyete göre dağılımları.

$\begin{array}{lccc}\text { Bulgular } & \text { Toplam, } \mathbf{n}(\%) & \text { Kadın, } \mathbf{n}(\%) & \text { Erkek, } \mathbf{n}(\%) \\ \text { Normal bulgular } & 727(48.4) & 380(52.2) & 347(47.8) \\ \text { Hemoroid } & 225(15.0) & 115(51.1) & 110(48.8) \\ \text { Anal fissür } & 75(5.0) & 39(52) & 36(48) \\ \text { Ileit } & 18(1.2) & 8(44.4) & 10(55.5) \\ \text { Nonspesifik kolit } & 93(6.2) & 38(40.8) & 55(59.1) \\ \text { Crohn hastalı̆̆1 } & 21(1.4) & 10(47.6) & 11(52.3) \\ \text { Ülseratif kolit } & 30(\% 2) & 14(46.6) & 16(53.3) \\ \text { Polip } & 207(13.8) & 86(41.5) & 121(58.4) \\ \text {-Neoplastik polip } & 136(9.6) & 55(40.4) & 81(59.5) \\ \text {-Non neoplastik polip } & 71(4.7) & 31(43.6) & 40(56.3) \\ \text { Divertikül } & 60(4.0) & 27(45) & 33(55) \\ \text { Rektal ülser } & 15(1.0) & 7(46.6) & 8(53.3) \\ \text { Anjiyodisplazi } & 3(0.2) & 2(66.6) & 1(33.3) \\ \text { Lipom } & 5(0.3) & 1(20) & 4(80) \\ \text { Kolorektal kanser } & 21(1.4) & 7(33.3) & 14(66.6) \\ \text {-Rektum } & 6(0.4) & 3(50) & 3(50) \\ \text {-Sigmoid kolon } & 8(0.5) & 2(25) & 6(75) \\ \text {-Transvers kolon } & 2(0.1) & 1(50) & 1(50) \\ \text {-Çıkan kolon } & 4(0.3) & 1(25) & 3(75) \\ \text {-çekum } & 1(0.1) & 1(100) & 0(0)\end{array}$

üzeri kadın hastalarda $\% 15$, erkek hastalarda $\% 25$ olmalıdır. (7). Çalışmamızda kirli olan kolonlar değerlendirme dışı tutulduğunda çekuma ulaşma başarımız \%94.1 bulunmuş olup istenen ideal seviye olduğu gözlendi.

Sigmoidoskopinin aksine kolonoskopi kompleks bir inceleme yöntemidir. Proksimale doğru ilerledikçe yöntem daha zor ve hastayı daha fazla rahatsız edici bir hal almaktadır (5). $\mathrm{Bu}$ nedenle işlem öncesi tam ve yeterli bir bağırsak temizliği ile işlem sırasında yeterli sedoanestezi yapılması, hasta ve endoskopist için oldukça önemlidir. Çalışmamızda hastaların \%21.9'unda yetersiz kolon temizliği nedeniyle kolonoskopik incelemenin çekum ve terminal ileuma kadar yapılamadığ tespit edildi. Bu hastaların yeniden barsak temizliği yaparak ikinci kez kolonoskopi işlemine gelecek olmaları, ekstra iş yükü ve maliyet anlamına gelmektedir. Bundan dolayıdır ki, kolon hazırlığı konusunda gerek endoskopistlerin gerekse hastaların daha duyarlı olmaları gerektiği kanısındayız.

Amerika Birleşik Devletlerinde kolonoskopi yapılan erişkin hastaların \%50'sine varan oranlarda hemoroid saptanmıştır (6). Ülkemizde yapılan çalıșmalarda, Doğu Anadolu Bölgesinde bulunan Erzurum (9) ve Ağrı (10) ilinde sirasıyla
\%17.6 ve \%28.4, Kibris'ta (11) \%31, Düzce'de (12) \%21.3 oranında hemoroid saptanmıştır. Bizim kolonoskopi yaptığımız hastalarda, tek başına hemoroid tanısı alan hasta oranı \%15 iken anal fissür oranı \%5 olarak bulundu. Hemoroid bulgusu, normal kolonoskopi bulgumuzdan (\%48.4) sonra ikinci en sik kolonoskopi bulgumuzdu.

Kolon polipleri neoplastik ve nonneoplastik olmak üzere iki grupta toplanmaktadır. Neoplastik olanlar adenom ve karsinomlardan oluşurken nonneoplastik olanlar hiperplastik polip, juvenil polip, Peutz Jeghers polipleri ve inflamatuvar polipler olarak kendi içlerinde ayrllırlar (13). Poliplerin çoğu asemptomatiktir. Rektal kanama en önemli belirtileri olmakla birlikte, poliplerin boyutlarına göre kabızlık, gaitada değişiklik, barsak obstrüksiyonu, karın ağrısı ve ishal seyrek te olsa gözlenebilmektedir (14). Ülkemizde yapılan kolonoskopilerde; Elazığ'da (15) \%7, Bursa'da (16) \%13.4, Ağrıda (10) \%11.4 ve Düzce'de (12) \%6.4 oranında polip saptanmıştır. Bizim çalışmamızda kolon polipleri hemoroidden sonra \%13.8 oranıla ikinci sıklıkta tespit edilen kolon patolojisiydi. Bu poliplerin \%9.6'sı neoplastik, \%4.7'i nonneoplastik polip olarak saptandı. Kolon poliplerinin klinik açıdan önemli grubunu oluşturan adenomatöz polipler kolon poliplerinin 
2/3'ünü oluşturmaktadırlar ve kolorektal kanserlerin adenom zemininden gelişebilmektedir (17). Bu nedenle kolon ve rektumda saptanan her polip kolorektal kanserin öncü lezyonu veya kanser riski nedeni ile tam olarak çıkarılmalı, histolojik olarak incelenmeli ve patolojik tanının konması gerekmektedir.

Gastrointestinal sistemin en sik malignitesi olan kolorektal karsinomun her iki cins için hayat boyu gelişme riski \%13.2 olarak bildirilmiştir $(18,19)$. Siddique ve ark. (20) kolonoskopi yapılan 700 hastayı değerlendirdiklerinde, \%29.5'inde adenomatöz polip, \%12'sinde kolorektal kanser saptamışlar. Çalışmamızda kolorektal karsinom oranı \%1.4 olarak tespit edilmiş olup bu kanser saptama oranımız literatürün belirgin şeklinde altında bulunmuştur. Bunun sebebi kolonoskopi endikasyonlarını geniş tutmuş olmamız yanı sıra beslenme alışkanlıklarından dolayı kolorektal kanser sılklı̆ının bölgemizde az olmasından kaynaklanabileceğini düşünmekteyiz. Çünkü ülkemizin farklı bölgelerinde yapılan kolonoskopi çalışmalarında bu aran \%1 ile \%3,9 arasında bulunmuş olup bu çalışmalardaki verilerin de literatürdeki yabancı ülke verilerinden belirgin olarak düşük olduğu gözlenmektedir. Ayrıca çalışmamıda koleraktal kanserlerin \%66.6'sı sigmoid kolon ve rektumda saptanmıştır.

Ülseratif kolit, etiyolojisinde immünogenetik ve çevresel faktörlerin sorumlu tutulduğu, nedeni bilinmeyen kronik inflamatuvar bir kolon hastalığı olup; insidansı 3-15/100.000/yıl, prevalansı 80-120/100.000'dir (21). Ülkemizde kolonoskopi yapılan hastalarda ülseratif kolit sıklığı; Elazı ğ'da \%3 (15),

\section{KAYNAKLAR}

1. Minali G, Meucci G, Bartoli A, et al. The ASGE guidelines for the appropriate use of colonoscopy in an open access system. Gastrointest Endosc 2000;52:39-44.

2. Winawer S, Fletcher R, Rex D, et al. Gastrointestinal Consortium Panel: Colorectal cancer screening and surveillance: clinical guidelines and rationale-update based on new evidence, Gastroenterology 2003;124:54460

3. Smith RA, Cokkinides V, Brawley OW. Cancer screening in the United States, 2009: a review of current American Cancer Society guidelines and issues in cancer screening. CA Cancer J Clin 2009;59:27-41.

4. Lieberman DA, Weiss DG, Bond JH, et al. Use of colonoscopy to screen asymptomatic adults for colorectal cancer. Veterans Affairs Cooperative Study Group 380. N Engl J Med 2000;343:162-8.

5. Vennes JA. Gastrointestinal Endoscopy. In: Wyngaarden JB, Lloyd SH Jr, Bennett JC. (Editors). Cecil Textbook of Medicine, 19th Edition. Philadelphia: W. B. Saunders Company 1992; 630-4.

6. Smith RA, Cokkinides V, Eyre HJ; American Cancer. Society. American Cancer Society guidelines for the early detection of cancer, 2003. CA Cancer J Clin 2003;53:27-43

7. Rex DK, Bond JH, Winawer S, et al; Multi Society Task Force on Colorectal Cancer. Quality in the technical performance of colonoscopy and the continuous quality improvement process for colonoscopy: recommendations of the U.S. Multi Society Task Force on Colorectal Cancer. Am J Gastroenterol 2002;97:1296-308.

8. Rex DK, Petrini JL, Baron TH, et al. Quality indicators in colonoscopy Gastrointest Endosc 2006;63(4 Suppl):S16-28.
Düzce'de (12) \%0.9 olarak tespit edilmiştir. Bizim verilerimizde ülseratif kolit saptanma oranı \%2'dir.

Kolonoskopi invaziv ve diğer görüntüleme yöntemlerine göre daha pahalı bir işlemdir. Literatürde kolonoskopi sonrası \%0.24-\%0.33 oranında kanama, \%0.08-\%0.19 oranında perforasyon gibi komplikasyonlar bildirilmiştir (22). Kolonoskopi sırasında ortaya çıkabilen hipoksemi, hipotansiyon, taşikardi, miyokard iskemisi, bradikardi ve IV sedasyon sonrasında ortaya çıkabilen kardiyorespiratuar değişiklikler, kolonoskopinin komplikasyonları arasında sayılabilir (13). Kliniğimizde yapılan 1500 kolonoskopi işlemi sırasında perforasyon gözlenmedi. Buna karşın bir vakamızda midazolam ve pethidine ile yapılan sedoanesteziyi takiben anaflaksi gelişti. Hızla intravenöz olarak yapılan adrenalin, antihistaminik ve prednisolon müdahalesi sonrası yaklaşı 5-10 dk içinde hasta klinik olarak stabil ve normal hale döndü. Ayrıca özellikle yaşlı hastalarda kolonoskopi sonrasında sık hipotansiyon gelişebilmekte, bu yönden gerek görüldüğünde IV sivı vermek için işlem öncesinde ve sonrasında hastaların tansiyonları ölçülmelidir.

Sonuç olarak alt gastrointestinal semptomu olan hastaların kolorektal hastalıklarının benign ve malign patolojilerin tespitinde kolonoskopi halihazırda altın standart bir yöntemdir. Bunun yanında büyük oranda normal kolonoskopik bulgularımızdan dolayı endikasyonların çok geniş tutulduğu görülmüştür. Ayrıca barsak temizliğinin yaklaşık beş hastanın birinde yetersiz olduğu, bunun da ekstra bir iş yükü ve maliyet getirdiği tespit edilmiştir.

9. Balık AA, Çelebi F, Atamanalp SS, et al. Alt gastrointestinal sistem endoskopi sonuçlarımız. Atatürk Üniversitesi Tıp Dergisi 2000;32:101-4.

10. Şit M, Aktaş G, Yılmaz EE. Alt gastrointestinal endoskopi sonuçlarımız: Ağrı Doğubayazıt Bölgesi. Kocaeli Tıp Dergisi 2012;3:1-4

11. Izbul T, Akalın M. The evaluation of diagnostic rectosigmoidoscopic examinations in Turkish Republic of Northern Cyprus. Turk J Gastroenterol 1999;10:268-71.

12. Yaşar M, Kayıkçı A. Kolonoskopi sonuçlarımızın retrospektif analizi. Konuralp Tip Dergisi 2010;2:6-9.

13. Boland CR, Hzkowitz SH, Kim YS (Editors). Colonic polyps and gastrointestinal polipozis syndromes. Gastrointestinal disease, Sleisenger $\mathrm{MH}$, Fordran JSS, Philedelphia ,WB Saunders Company 1989;2:1483-1518.

14. Winawer SJ, Zauber AG, Fletcher RH, et al; US Multi-Society Task Force on Colorectal Cancer; American Cancer Society. Guidelines for colonoscopy surveillance after polypectomy: a consensus update by the US Multi-Society Task Force on Colorectal Cancer and the American Cancer Society. Gastroenterology 2006;130:1872-85.

15. Bahçecioğlu IH, Güzel Z, Çelebi H, et al. 1990-1995 yılları arasında kliniğimizde yapılan rektoskopi ve kolonoskopi sonuçlarının değerlendirilmesi. Gastroenteroloji 1996;7 (Supp 1):107.

16. Dolar ME, Gültekin M, Nak SG, et al. Kolonoskopik incelemenin değerlendirilmesi. 9. Ulusal Türk Gastroenteroloji Kongresi. 1994, P: 410.

17. Heitman SJ, Ronksley PE, Hilsden RJ, et al. Prevalence of adenomas and colorectal cancer in average risk individuals: a systematic review and meta-analysis. Clin Gastroenterol Hepatol 2009;7:1272-8. 
18. Sànchez A, Munoz C, Bujanda L, et al. The value of colonoscopy to assess rectal bleeding in patients referred from Primary Care Units. Rev Esp Enferm Dig 2005;97:870-6.

19. Tamer A, Korkut E, Korkmaz U ve ark. Alt gastrointestinal endoskopi sonuçlarımız: Düzce Bölgesi. The Medical Journal of Kocatepe 2005;6:2931 .

20. Siddique I, Mohan K, Hasan F, et al. Appropriateness of indication and diagnostic yield of colonoscopy: First report based on the 2000 guidelines of the American Society for Gastrointestinal Endoscopy. World J Gastroenterol 2005;11:7007-13.
21. Russel MG. Changes in the incidance of inflammatory bowel disease: what does it mean? Eur J Intern Med 2000;11:191-6.

22. Viiala CH, Zimmerman M, Cullen DJ, Hoffman NE. Complication rates of colonoscopy in an Australian teaching hospital environment. Intern Med J. 2003;33:355-9

23. Garbay JR, Suc B, Rotman N, et al. Multicentre study of surgical complications of colonoscopy. Br J Surg 1996;83:42-4. 